\title{
In Situ Hybridization
}

National Cancer Institute

\section{Source}

National Cancer Institute. In Situ Hybridization. NCI Thesaurus. Code C17562.

Use of a DNA or RNA probe to detect the presence of complementary sequences in chromosomes, cells, or tissues. 